\title{
An Expanded Understanding of Art as an Agent of Change in Higher Education
}

\author{
Anika van den Berg, Karolien Perold-Bull, Elmarie Costandius*, Neeske Alexander, \\ Danielle Becker
}

Department of Visual Arts, Stellenbosch University, Stellenbosch, South Africa

Email address:

anika@mxmstudio.co.za (A. van den Berg), elmarie@sun.ac.za (E. Costandius)

${ }^{*}$ Corresponding author

To cite this article:

Anika van den Berg, Karolien Perold-Bull, Elmarie Costandius, Neeske Alexander, Danielle Becker. An Expanded Understanding of Art as an Agent of Change in Higher Education. American Journal of Art and Design. Vol. 5, No. 4, 2020, pp. 87-96. doi: 10.11648/j.ajad.20200504.12

Received: October 24, 2020; Accepted: November 16, 2020; Published: November 24, 2020

\begin{abstract}
South African higher education institutions seek strategies to address belonging and decolonization. The student protest movement across South African university campuses during 2015-2016 further underlined this fact. We explored the capacity of interactive artworks to address belonging and active citizenship, both prioritized by university management. Art, in this sense, facilitates out-of-classroom education to aid the institutional decolonial vision of a university entrenched in colonial history and apartheid. Furthermore, the protests challenged the slow pace of institutional change at South African universities. This article examines responses to an interactive artwork placed on the Stellenbosch University campus. Our elastic understanding of art and education deviates from traditional art history and acts as a critical public intervention that aimed to stimulate conversation about belonging at Stellenbosch University. The employed research methods are informed by the decolonial framework which engages a crucial attentiveness of the power issues embedded in knowledge production, validation and dissemination. An interactive public artwork, titled "We Belong Here", was placed on the main campus of Stellenbosch University in South Africa. We invited students on campus to make visual statements related to topics such as community, apathy, legacy, honour, protest, ethical conduct and creativity. Qualitative data was gathered from individual and group interviews with students, lecturers and staff members who were most likely to have encountered the artwork. Theories on critical citizenship education, and art education informed the research and discussion. The data suggests that art education in the expanded field has the potential to aid higher education institutions in bringing about personal and intellectual growth. Both accepting and dismissive opinions were raised by participants and welcomed by the researcher. Viewing their voice among many, led some to a sense of belonging in the university community, and their interaction led them to converse with others on the topic of citizenship. There was also criticism to the artwork text written in English, and concern that such a work could not create any relevant impact. Although the parameters of the artwork is limited within the field, the student protest movement was a forceful reminder of urgent matters in higher education and a reason to continue enquiry and interventions to decolonialize education.
\end{abstract}

Keywords: Critical Citizenship, Education, Public Art, Transformation, University

\section{Introduction}

Art can be a powerful vehicle that includes people, aids social cohesion, addresses issues of social justice, and facilitates the complex process of transformation in communities. From this understanding of art, we explore possible interactions between education, non-education, art, and non-art. This extended definition of art, or 'the expanded field', allows a repositioning of these terms with indefinite elasticity so as to broaden the potential for discussion [1].

This article explores how art education in the expanded field can aid higher education institutions in fulfilling their transformative role. An interactive public artwork was placed on the main campus of Stellenbosch University, South Africa, to explore its effect on students. Data was gathered from individual and group interviews and analyzed by inductive content analysis. The method allowed for navigation between interdisciplinary landscapes so as to pick up on nuanced information. Participants' reactions revealed the particularity 
of the Stellenbosch University context, the potential of art in the expanded field, and perceptions of citizenship. Literature and policy documents from various contexts were surveyed, although the study itself was limited to the educational capacity of art on the Stellenbosch University main campus. The circumstances that surrounded this study were a of the student protest movement that erupted across all university campuses in South Africa during 2015-2016.

\section{Theoretical Perspectives}

\subsection{Decolonization}

This study was positioned within the broad context of anti-colonial theory, or what is more commonly referred to as decolonial theory. This perspective promotes a critical awareness of the power struggles embedded in educational practice, and challenges educators to reconsider the locations of knowledge [3]. Within anti-colonial theory, colonialism is seen as any form of "imposition and domination" that exists as a result of the historical occurrence of European colonialism [3]. Anti-colonial scholars labour to challenge Eurocentric discourses with new insights and to enable indigenous intellectual and political freedom [3]. This article draws on anti-colonial and decolonial theory in debating the perspectives relevant to the case study and the context of ideological change within higher education.

\subsection{The Expanded Field}

Rosalind Krauss's [1] postmodern concept of the expanded field sees finite modernist terms as "stretched and twisted in an extraordinary demonstration of elasticity", resulting in categories that are "almost infinitely malleable". Elastic understandings of art and education situate the discussion within 'the expanded field'. Through problematizing the sets of oppositions between which modernist categories are suspended the expanded field was explored [1]. A set of binaries is transformed through a logical expansion into a "quaternary field", which both mirrors and opens the original contradictions [1]. The suspension of sculpture between non-architecture and non-landscape opens up other possibilities between the domains of landscape and architecture, of which sculpture is merely "one term on the periphery of a field in which there are other, differently structured possibilities" [1]. This field therefore sanctions an expanded but finite set of related positions to be explored outside the conventions of a particular medium or field [1]. When the traditions context of art history was abandoned the new framework allowed the creation and analysis of the artwork, not in the traditional context of art history, but as a critical public intervention aiming to stimulate conversation. Therewith enabling the evaluation of the work from a public perspective, using the research data from interviewed candidates with various degrees of visual literacy.

\subsection{Relational Esthetics}

Relational aesthetics is a useful tool in studying the potential of art to revitalize possibility in people's minds. It refers to the bonding capacity of art to bring people together. Artworks are created with the function and intention of catalyzing relationships [4]. Applying the perspective of relational aesthetics, the collective social space is preferred over the symbolic private space, or rather, the public space is given preference over the museum or gallery space [4]. The notion of relational art indicates a profound disruption of the cultural, aesthetic, and political aims of modern art [4]. An artwork therefore becomes an instrument to link individuals together and reinforces unity without relying on uniformity The interactive nature of relational aesthetics results in transparency" that enables artworks to continue existing beyond the boundaries of time and space into discussions and negotiations of identity, experience, and truth [4].

Because relational aesthetics looks at the way in which discussions are catalyzed by participation, artworks that are framed in this way tend to occur in public spaces. Art that occurs in the public realm often seeks to facilitate the methods by which a community perceives, learns, and assembles. This method of art production therefore has the potential to serve communities. Public artworks, particularly those that operate with relational aesthetics in mind, could be regarded as a form of public education.

\subsection{Critical Citizenship}

Laura Johnson and Paul Morris [5] define citizenship as the "promotion of a common set of shared values which prepare young people to live together in diverse societies". The specific common values to which they refer are tolerance, human rights, and democracy, and their outcomes include social justice and diversity [5]. Citizenship education needs to be "cross-disciplinary, participative, interactive, related to life, conducted in a non-authoritarian environment, cognizant of the challenges of societal diversity" [5]. While citizenship applies to an entire society, Johnson and Morris [5] connect it to higher education by forging a link between critical thinking and critical pedagogy to propose critical citizenship education. Critical thinking is a process that enables students to include a deeper understanding of values and power relations in their opinions and arguments [5]. Critical pedagogy refers to a body of literature that provides educators with instruments to develop a sense of agency in the oppressed so that their reflections on their own conditions can lead to improved action [5]. Critical citizenship education implies "the emancipation and transformation of students... toward a better society" [5]. This is a particularly relevant concept considering the context of this case study and was referenced in discussion with the interview participants. The notion of critical citizenship is used in this article as a way of discussing a sense of responsibility among participants and is extended to the notion of citizenship education as an alternative form of education.

Education for social justice is seen as a means for students to obtain credible information sources, develop honest personal reflection, question their former assumptions, and formulate appropriate understandings of their social roles and 
responsibilities [6]. Some of the 'core frameworks' that underlie social justice education are balancing emotional and cognitive learning, complementing individual and collective learning, vital social interaction in the classroom, reflection on experience, and rewards for personal growth [6]. This article employs these terms as part of its discussion.

\subsection{Art as Education}

Art (particularly public art, as mentioned above) is perceived as a means for education, or specifically critical citizenship education. Artistic production can, from this perspective, create a platform for "social self-awareness" and be "an instrument of human liberation" [7]. "Artistic citizenship' refers to the grounded artist, as opposed to the ignorant artist, who can perform "a particular kind of social good" by inspiring ideas and attitudes about shared living and communal identities [7]. The case study explores in this article situated art within education.

\subsection{Transdisciplinary Knowledge}

Knowledge within the art education context is by its very nature transdisciplinary, as it exists between the traditional disciplines of education and art history or theory. Maxine Greene [8] asserts that the expansion of the boundaries of valid and appropriate knowledge activates students' social imagination - their ability to visualise possibilities and the latent capacities of their society. She encourages active learning through discourse and participation [8], which awaken students to the vitality of possibility and the need for action [9]. Active learning is education that leads to dialogue between different cultures and social groups, which prompts students to ask more questions and develop their own reasoning. Educators are encouraged to think beyond schooling to the larger domains of education [8]. According to Greene [10], art education can help individuals recognize the connections between themselves and their communities. She believes that "encounters with the arts" foster individual growth in terms of relational capabilities, inventiveness, problem solving, and zeal for living [11]. We could therefore apply theory from a variety of disciplines which deal with notions of critical citizenship and education, while building on theory from the fields of art history and visual studies.

\section{Context}

Many universities around the world are attempting to 'transform' their curricula, their campuses, and indeed their view of higher education to reflect current cultural reality. It is the colonial origins of many aspects of higher education and the way in which colonialism has been intertwined in racism that have catalyzed what has become known as the decolonial movement. Indeed, the discourse has intentionally shifted from the use of the term 'transformation' to 'decolonisation', as the former is seen to be a homily linked to generic attempts to change university structures and more sinisterly as a justification for the commodification of knowledge under the guise of change. For many, 'transformation' refers to "access and success, social inclusion and cohesion in institutional spaces" [12], yet the term also represents deep concerns regarding exclusion, belonging and the slow pace of change. In this article, the term 'transformation' is used with an acknowledgment of its limitations and contestations, and the term 'change' is preferred when writing about general shifts and 'decolonization' when these shifts apply to a colonial past.

South Africa exists in a particular relationship with the notion of decolonization intensified by a colonial past as well as apartheid. As such, there were fervent student protests at most universities in South Africa in 2015 and 2016. Student protestors called for radical change and an end to the slow pace of institutional change since apartheid officially ended in 1994. Stellenbosch University's protests were led by a group known as Open Stellenbosch, which called for curriculum change, an end to racism, and a change in the language of instruction from Afrikaans to English. Afrikaans is perceived as the language of apartheid, as it was linked both culturally and linguistically to the apartheid government. Stellenbosch University has also, historically, been designated as a white, Afrikaans university. Many (though not all) black South Africans do not speak Afrikaans and so feel excluded by its use. The protests in Stellenbosch took on a different character to those in Cape Town and Johannesburg as a result of the specific context of the University town. The colonial history of Stellenbosch University poses a challenging obstacle to decolonial movements, as the University formerly played a key role in apartheid policy formation and Afrikaner nationalism, but is now trying to establish itself as a 'transformative, diverse agent of change' in a democratic South Africa. Stellenbosch University is what is referred to as a 'historically white University': one that was reserved for those classified as white during apartheid. It is also a contemporary space with a staff and student body that is still predominantly white. The institution, however, wants to position itself as a space that harnesses diversity and change. The vision applicable to the 2013-2018 period stated that Stellenbosch University is determined to be an "inclusive, innovative and future focused" institution; "a place of discovery and excellence where both staff and students are thought leaders in advancing knowledge in the service of all stakeholders" [13]. Terms such as 'transformed', 'integrated' and 'inclusive' are therefore used in official documentation as somewhat subtle nods to the need to change the racial diversity of the institution and its curricula.

One of the criticisms of the institutional use of the term 'transformation' is that it is often reduced to a statistical value, which neglects the underlying Eurocentric and patriarchal culture in the very fiber of the "historically white universities" [15]. In response to the student protest movement of 20152016, Badat [15] maintains that higher education institutions in South Africa have "yet to succeed in uprooting inherited cultures and practices and bringing about the far-reaching transformations that are necessary and long overdue". For many, terms such a 'transformation' and 'inclusion' are far generic and do not allow for specific strategies to challenge 
Eurocentric discourses [3]. These strategies are needed to allow universities to negotiate between their colonial heritage and the contemporary socio-economic challenges that South African graduates need to address. As mentioned above, and ideological 'transformation' of university spaces has also been claimed as the catalyst for a change in the nature of institutional learning in general. Universities globally are taking on corporate models that for many do not allow for the historical focus on critical thought.

Institutions such as Stellenbosch University face challenges in the light of the context of decolonization and more general attempts at ideological change. The case study in question was conducted in an effort to ascertain what effect community engagement though public art can have. Public art is seen, from this perspective, as a platform for "social self-awareness" [7] that reinforces communal identities [7] and tightens the space of interaction through tangible symbols [4]. Applying this perspective, art becomes a means to create community engagement that is in line with Stellenbosch University's view of creating, for instance, a critical student body finding expression through the "transformation of society that involves transformation of the selfh[s 6xplorative case study investigated students' reactions to an interactive public artwork set up on the Stellenbosch University main campus in celebration of 20 Years of Freedom and Democracy. In 2014, the nation of South Africa celebrated 20 years since the first democratic elections and Stellenbosch University, led by its Centre for Inclusivity, held a number of events to mark this national milestone. The Centre for Inclusivity was set up by former rector and vice-chancellor Russel Botman, who died in June 2014. Prof. Botman was the first black vice-chancellor and came under enormous pressure as a result of his attempts to change Stellenbosch University's policy in order to create a more equitable and less racist institution. With the death of former rector and vice-chancellor Russel Botman in June of 2014, the struggle with creating change began to reach a critical point. The tensions that ensued in 2014 were part of the trajectory that led to the 'Fees Must Fall' student protests beginning in October 2015. As Greer Valley [17] wrote in October 2014, "[t] ransformation is a messy process which may need to involve confrontation and contestation" rather than celebratory events that tend to create "a diversion from the real challenges facing the institution". In part, it was the frustration that students felt with the pace of 'transformation' at various campuses in South Africa (including Stellenbosch) culminating in student protests. Badat [15] agrees that student protestors were frustrated with "the slow pace of change in the institutional cultures, in the academic staff body, and in important aspects of the academic programs of the historically white universities". He reasons that students were "demanding greater social justice in higher education" based on the objectives stipulated in the Constitution including institutional policy documents [15].

At Stellenbosch University, many attempts have been made to put policies in place that negotiate and rectify the complex history of racism, systemic exclusion, and gross inequalities in higher education. The Soudien Report, for example, focusses on racism in university residences [18], while on a National level the Ministerial Committee on Transformation [19], and the mergers proposed in the National Plan for Higher Education of 2001 [20] all address the issue. Higher Education South Africa's policies [19] stress a need for "a climate of honest and open debate" in facilitating thorough transformation. Thorough transformation refers to more than policy implementation, including both formal processes of education and everyday practices such as traditions, customs, habits, and symbols [19]. This focused, albeit volatile, context of transformation in higher education is the milieu in which the research for this article was conducted.

With the above context in mind, this article discusses the way in which one interactive public artwork commissioned by the Centre for Inclusivity could bridge the gap between institutional policy and practice at Stellenbosch University. The artwork in question formed part of a week-long celebration of 20 Years of Freedom and Democracy on campus. The late rector and vice-chancellor, Prof. Botman, established the center to report directly to his office as a chief strategic priority. Their brief for the interactive artwork specified that it should engage students in a conversation about their sense of belonging at Stellenbosch University. The response resulted in an interactive public piece with the statement "We Belong Here" weaved with fabric into a black mesh structure (see Figure 1 错误!未找到引用源。). Five clear containers were added, each holding fabric strips in the colors of the South African flag. Each of these containers had a statement about citizenship on it with which members of the public could choose to identify through their color choice. Instructions described the artwork as "our visual illustration of how we see a community where everyone can belong" and invited passers-by to "grab pieces of fabric from any of the containers" and "weave it anywhere into the wire".

The statements on the containers were the following:

1. Let us celebrate the uniqueness of our community and consider the impact of our actions on one another. (Green)

2. Apathy is lethal. Let's turn our ideas into actions, thinking about our legacy. (Red)

3. A culture of honour and respect can take us further than one of riots and protests. (White)

4. Our only tool to disarm corruption is standing for unbending, ethical conduct. (Yellow)

5. Let's ignite hope for our country by sharing our creative ideas and gratitude rather than our complaints. (Blue)

The primary objective of the artwork was to engage students in conversation on their choice of colors as they corresponded to the statements listed above. By design, the artwork became more esthetically interesting as participation increased, bearing nuances of the South African flag without obvious visual cues. The artwork positioned itself as a public learning opportunity aiming for an experience that would further education outside of the conventional space of the lecture hall (cf. [2]). 


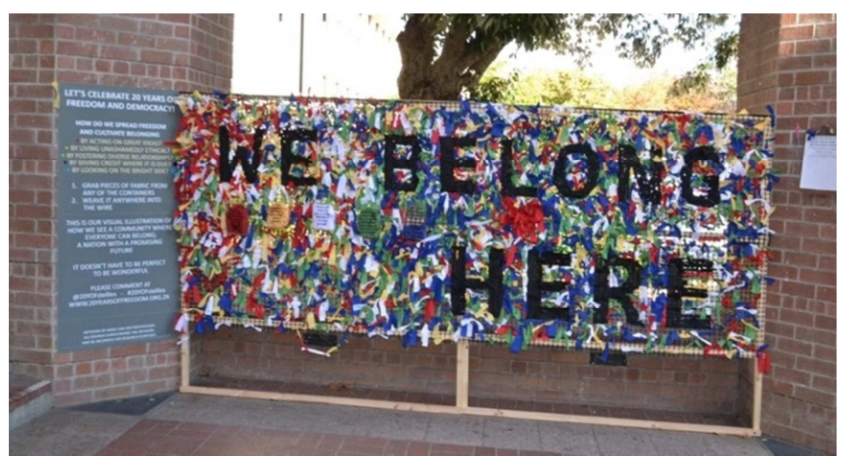

Figure 1. "We Belong Here" (16 May 2014; 17:30). This image shows the artwork on the last day of interaction with it.

\section{Methodology}

A case study research design was employed for this study, as this was seen as most applicable where a single case is placed in an expansive framework or context (cf. [21]). The research was qualitative in nature and made use of an interdisciplinary landscape of theoretical perspectives (cf. [22]). Through the interpretative paradigm, the social connotations that individuals assign to their exchanges were studied (cf. [22]). Interviews were used to collect responses, as interviews are seen as an effective means of extracting complex sets of information being sensitive to nuance. Group and individual interviews were allocated through non-purposive judgement sampling. Individuals or groups who were most likely to have encountered the artwork were selected. These participants had opinions regarding higher education or the intrinsic capacities of art education in the expanded field. The interviewees consisted of two lecturers, twelve students, and three other staff members who work with students at Stellenbosch University. The lecturers were situated in the Education and Science faculties. The students were from a spectrum of faculties, courses, and year groups. The staff members were from different support departments.

Interviews were recorded using an electronic voice recorder. The data generated during interviews were coded through the process of open, axial, and selective coding (cf. [21]). Interview participants were divided into three groups, namely staff members who work with student affairs (SM), lecturers (L), and students (S).

Participant feedback was analyzed using inductive content analysis, a "creative reasoning mode" aiming to open up possibilities rather than reach finite conclusions [21]. The inductive content analysis was a valuable method for dealing with complex and evasive concepts and for proposing a new understanding of existing issues.

\section{Participant Responses}

Participants' responses to the interactive artwork "We Belong Here" are presented below. These reactions were considered in relation to Stellenbosch University's particular context and the nature of the artwork in question. The responses were divided into five themes that respectively deal with the nature of interactive art on a university campus, ideas about 'transformation', educating for critical citizenship, safe spaces at higher education institutions, and citizenship as belonging.

\subsection{Interactive Art on Campus}

The interactive artwork "We Belong Here" invited participants to contribute to an abstract visual illustration of an imagined community where everyone can belong. A number of participants commented on the nature of public, interactive art and its capacity to engender discussion. Many were interested in the possibility of participating in the creation of an artwork. Student S7 observed that "people have a lot of preconceived ideas about what art is" and maintained that "people actually don't realize the value of art, participating in it" unless art is "taken out of its gallery space and put into public spaces". Others were excited about being able to voice concerns through the platform of public art. "It's so cool that art and the more political side of the country can be brought together", was a surprised remark by S10. Participants who responded positively to the artwork felt willing and able to participate. It seems that many people were visually drawn to the piece. "I watched it for a while and the people walking past were immediately drawn to it", responded S12. S9 commented, "It looked very interesting and intriguing from the outside" and elaborated by saying, "I was so excited to partake", "students enjoyed it immensely", and "I actually heard in res [student residence] people talk about how they put up a color today". S9 described the location of the artwork as "the most central part of campus" "where variety and diversity [are] at [their] best", and where "anybody on campus could partake in it". According to S8, people responded to the visual imagery quickly and clearly: "You stand back and you see your voice among many... If people are exposed to such visual metaphors regularly, subconsciously they will start seeing that what they do makes a mark - that it matters." The aforementioned comments urge the conclusion that for many, the appearance and nature of the artwork encouraged participation, that participants understood how to engage with a public artwork, and that participation led to a sense of community involvement.

These positive perspectives were not shared by all, however. Negative responses questioned the potential effect of interactive art as well as the title and message of the artwork. S13 said that "mostly my friends will have mixed feelings towards this". Lecturer L2 mentioned that people might interpret the slogan "We Belong Here" as "a militant statement", while S7 attributed criticism to the language, saying, "I don't know how people would have reacted to it being in English". Stellenbosch University provides teaching and learning in English and Afrikaans, but has historically been an Afrikaans university. Debates on language policy and practice were central to the student protests at Stellenbosch University during 2015 and 2016, coordinated by Open Stellenbosch, which succeeded in having a new language policy instituted in 2016, which means that no student may be excluded from tuition as a result of not speaking Afrikaans. L2 
remarked that "[the artwork] might probably be so simple that it flies below the radar", which was substantiated by the following comments: "Projects like these, when it's done on the whole university, loses the personal touch that it needs" (S4); "I just ran past it a few times, I never really stopped" (S1), and "If I was more curious and inquisitive to know what it stood for... it would have made a greater impact" (S5). The comments suggest that viewers perceived the work either as divisive or as incapable of creating any relevant impact or failed to grasp its goals.

When questioned on the merit of art as a vehicle of citizenship education, SM3 replied that this method "breaks it open for people, people see things, it's one of the best ways for people to learn". According to L1, "educating people about democracy and democratic ideals through the medium of art provides a translation into practice of philosophical ideas" and therefore makes it "accessible to ordinary people". SM2 stated that it helped people sharpen their thoughts about the topic and to have conversations. SM2's remark correlates with relational aesthetics where artworks seek to ignite conversations and function as citizenship models [4].

\subsection{Transformation}

The participants interchangeably referred to 'transformation' as a change in thinking and a change in institutional culture. The term represents deep concerns regarding exclusion and belonging and has been seen, as stated above, as indicative of the slow pace of change in ideology at many South African universities. These concerns surfaced in the Open Stellenbosch movement's calls for a change in institutions' language policies [12]. The students who engaged with the artwork in question identified a lack of focus, political agendas, and insufficient leadership transformation as matters of concern. They also identified the University as presenting an uncomfortable space for black students in terms of culture, physical spaces, and ideology. As one student described it, "In many ways the University is actually a reflection of... a very European setting; students come here with that kind of mentality" (S7). L1 described Stellenbosch University's institutional growth, saying it needs to be "flexible and changeable and open to transformation of all kinds; not only politically inspired transformation... but also ideas". S7 bluntly stated, "There's not enough transformation to actually show that twenty years of democracy impacted Stellenbosch" and that "a more aggressive form of transformation" should be implemented. SM1 stated, "It's still a struggle", "we think we've gone a far way", but "we've come a little way". "I get the idea that the University is a bit confused about where it wants to go", was S3's opinion. S11 argued that "the University must not do stuff just to be political about it, students don't like that and that creates antagonism rather than solutions", which echoes several other participants' skepticism towards superficial transformation. S7 posed the question: "If the students don't see transformation in positions of power, then how are they going to want to do it themselves?"

\subsection{Educating for Critical Citizenship}

In response to the artwork "We Belong Here", some participants identified the ways in which the work pointed to a need to create dialogue and learning opportunities outside of the lecture environment that promote critical citizenship and active engagement in concerns regarding 'transformation'. S7 pointed out "a disjoint from what the vision is and what happens on campus". This disjoint was substantiated by S9's experience, who said, "Never have I been confronted with these questions [about citizenship and transformation] in an academic framework". S9 continued that citizenship was addressed in their residence and in leadership development workshops. This implies that the support departments at Stellenbosch University (which include residences and the Centre for Inclusivity) are perceived as greater vehicles of the University vision than the classroom environments. S5 suggested that "those who participated, they gained something, or they received new knowledge".

The artwork appeared to create the sense that students were able to form their own connections and make meaning of the subject matter at hand. Some participants felt that this form of reciprocal knowledge transfer required greater emphasis at the University. "I don't think the University realizes the potential of students, how innovative they are and how deeply they think about stuff', was SM1's opinion. The feedback suggested that the artwork had the potential to capitalize on the creative potential of both students and educators to recognize sources of knowledge that are beyond the norm. As SM3 described, "What we are doing is really helping to bridge this divide between in-the-class and out-of-class experiences. The more collaboration we have between academic departments and support departments - it will help the students increase their integrated thinking about life". SM3 emphasized that engaging in learning needed to happen for staff as well as students: "We always focus on student learning, but not so much on the lecturers' and staff members' learning."

\subsection{Safe Spaces at Higher Education Institutions}

The feedback revealed that the artwork was a safe space for certain individuals, while peer opinions and social awareness caused anxiety for others. Fear of rejection and feelings of despondency made it difficult for some to share their personal views. SM2 pointed out "how intimidating sometimes the space of a university is for people to participate, and I just think we are unrealistic about that in terms of encouraging people to express their views". According to S2, "there's tension between different ideas". S1 stated, "They don't want to put themselves out there for the fear of people asking them and them having to defend their standpoint", which is "intimidating, so someone who is not used to sharing their opinions might not be comfortable". L2 said, "Those kinds of hidden things... come out in spaces where you create some trust; if you don't create that space... it doesn't happen". 
SM2 mentioned "finding your voice" as a key to citizenship, suggesting that the University should "respectfully and gently make people feel like their opinions are important". S5 remarked, "At Stellenbosch they encourage people to question stuff and not just take things as they are". Another student felt that initiatives such as the public artwork in question were "making spaces for conversation" (S7). Other participants pointed out what they saw as the importance of learning "to deal with other people's points of view and maybe alter yours in positive ways when you hear ideas from other people that you haven't necessarily thought of before" (S12). Another student reflected on the need for people to "analyze things and think about their own ethical stance on things" and to "be willing to be wrong in comparison to other people" (S9).

The sense that the artwork sparked conversation was echoed by a number of other participants. S9 stated that “even though people didn't partake, they spoke about it... and if people start conversing about issues that actually matter, that's great". SM3 felt "privileged to be in a space like a university to challenge and be challenged, where we can give space and wings to ideas". S9 heard "people talk about how they put up a color today" and S8 remarked that there was "enough space for people to approach it in groups", which suggests that the artwork stirred a discourse and created a space where students were free to express their opinions. S13 also related that "people have come together around the artwork, and then people will hear we have different opinions and maybe start talking about it".

\subsection{Citizenship as Belonging}

Varying expectations of citizenship emerged in the responses to the artwork. Citizenship relates to belonging, but many students do not experience a sense of belonging on South African campuses. This is due to a nuanced set of factors that include racial demographics, geographical layout, campus architecture, language, economic levels, and proximity of residence to campus. As Valley [17] points out, "Stellenbosch consists of a town center reserved for 'white' people during Apartheid by the Group Areas Act (1950) surrounded by spatially disconnected and racially segregated suburbs and townships". As a result, the town and campus exist in a suburb that is still dominated by a white population and this imbalance is transferred to student demographics: "In $2018,58.1 \%$ of enrolled students were white, $20.1 \%$ African black, $18.1 \%$ coloured, $3.1 \%$ Indian and $0.2 \%$ Asian" [23]. This is in a country where, as of 2010 , "79.4 percent declared themselves to be Black African while 9.2 percent were shown as White, 8.8 percent colored and 2.6 percent Indian or Asian" [24].

A sense of 'being' and 'belonging' were the starting points for the artwork in question. 'Belonging' is the lived experience and emotional counterpart to theories of citizenship and the term was mentioned by several participants. S13 affirmed "the first step is to feel a sense of pride and belonging before [students] can move towards higher education or learning". Psychological security is a key priority in social justice education, which is unreservedly "participatory, inclusive and affirming of human agency" [6]. S7 remarked that the artwork was "thought-provoking" because "people got to think about whether they do belong in Stellenbosch or not". 'Belonging' is a subjective concept and there are many who do not feel a sense of belonging at Stellenbosch University. "Even though you live [in Stellenbosch], you might not feel that you belong here", was S13's opinion. S7 said, "There's a certain stereotype that goes with being a Matie [a nickname for a Stellenbosch University student]; there's this ideal that you always have to work towards". These responses reveal that living and belonging are not parallel. S5 remarked that when some of her peers "see the word 'belong', they get offended with that, because they don't know what it really means to belong". According to S7, "a lot of students don't feel like they belong in Stellenbosch".

Some of the participants' responses highlight the very polarized positions that exist within the culture at Stellenbosch University. While groups such as Open Stellenbosch protested institutionalized racism at the University and positioned themselves against the ideology of authority, others felt they want to maintain the status quo. S12, for example, spoke about citizenship as "being... a person that contributes in a positive manner to society. When you don't break down structures and you don't go against authority, you are a good citizen". S12's opinions about citizenship raise difficult questions about the type of critical citizenship evident in the student protest movement. S12 remarked that citizenship is about building up and not breaking down in rebellion. The 20152016 student protest movement started out peacefully, but was, by the end of 2016 , characterized by violence, severe disruptive tactics, and the burning of a car and buildings [25]. The protesters chanted "burn to be heard", claiming change is improbable "unless the 'normal' functioning of an unequal educational system is disrupted" [25]. While these actions were perceived as necessary by those seeking change, others, such as SM2, perceived their actions as examples of "collective victimhood". While some participants highlighted the need to crate change in order to allow for a sense of belonging, others felt that any kind of disruption or change was unnecessary. For some, belonging felt inevitable: "When I think of citizenship, I just think of belonging" (S3); "I don't think you have to do anything, you just have to be from there" (S3); "This is our country, this is our university, this is where we grow, where we learn, where we make friends; we belong here" (S12).

The premise of Rhodes University's former vice-chancellor, Dr Saleem Badat, for the student protest movement resonates strongly with the above-mentioned responses. Badat [15] points out that "at the historically white universities" (such as Stellenbosch University), white students generally perceive the environment as "natural", they feel "at home", they thrive, and they are "largely oblivious to the association of the current cultures with power, privilege, and advantage". Black students and students from less affluent communities, on the other hand, tend to 
experience the environments and cultures of the historically white universities as "discomforting, alienating, disempowering, and exclusionary", which disables any possibility for university life to be "an enriching and liberating adventure" [15]. Badat [15] further points out that the student protest movement was a "forceful" and "dramatic reminder of unfinished business in higher education" that raised key issues: decolonization of the university, the social composition of academic staff, institutional culture, the inadequacy of state funding of higher education, the level and escalation of tuition fees, student debt, and the question of free higher education. Behari-Leak, Ramugondo, and Kathard [26] of the University of Cape Town contend that student protestors "wanted to disrupt their faculty's traditional power structures and the practices that made them feel like they were not worthy and didn't belong". They maintained that students felt "unheard" and that "healthy, meaningful dialogue between students and academic staff, genuine listening and a deep understanding of students' demands could make all the difference" [26].

\section{Discussion}

The participant responses hint at the way in which critical citizenship catalyzed by public art can inspire ways of thinking about shared living and communal identities [7]. There were positive and negative responses to the artwork, but most people still responded well to the idea that interactive art could be a tool to facilitate conversations on citizenship. In this sense, the artwork succeeded in catalyzing an interaction that would fall under the umbrella of relational aesthetics. The immediate and compelling manner in which people responded to the visual communication used in "We Belong Here" demonstrates Campbell and Martin's [7] description of public art as "a way of seeing, a way of knowing and a way of gathering". The public artwork can be seen as a way of seeing an individual voice among many, a way of knowing that people have different opinions, and a way of gathering around the contested topic of belonging at Stellenbosch University. Education, when seen from the perspective of critical citizenship, is not mere knowledge transfer, but guidance of students' thoughts and conversations Using art in such a style of education may prove to be a worthwhile instrument in steering individuals to recognizing the connections between themselves and their communities [10]. Greene [11] favors participatory artworks as a method to propel students towards affective, perceptual, and cognitive insights. The participants' responses echoed "the emancipation and transformation of students... toward a better society" [5].

The relational nature of the public artwork creates a platform for social self-awareness of 'transformation' that can be useful in catalyzing change [7]. It therefore has the potential to reinforce communal identities [7] and tighten the space of interaction through tangible symbols; in this case the visual symbols that were created in the public artwork through relational esthetics [4]. There is therefore scope for artworks to be used on campus as links not only between inand out-of-class educations, but also between the different support departments. Citizenship education is perceived as something that needs to be "cross-disciplinary, participative, interactive, related to life, conducted in a non-authoritarian environment, cognizant of the challenges of societal diversity" [5]. With this is mind, "We Belong Here" allowed for the creation of a transdisciplinary, real-life experience that was egalitarian in nature.

According to Greene [11], students gain from artworks when they exert energy and deliberately involve themselves in the artwork. This was seemingly achieved in the participation of students and staff in the artwork case study. We may see this as knowledge gained from a 'hidden curriculum'. The hidden curriculum is knowledge that is intentionally or unintentionally transmitted from educator to student, but that does not form part of the formal curriculum and official outcomes [27]. Learning in the space of the hidden curriculum takes place when diverse perspectives and social backgrounds converge between students, their peers, lecturers, and other staff members. Both educators and students can afford to expand their boundaries of knowledge [8]. The process of education involves both the formal and the hidden curriculum and results in a socializing force that assimilates students into the roles that they are to fulfil in their communities [28]. "We Belong Here" aimed to educate within the space of the hidden curriculum as catalyzed through interaction among participants through relational esthetics. An awareness of the exchange between perspectives is what creates community [29], and it could be brought about by the bonding capacity of art to ignite unrestrained conversations [4].

Higher Education South Africa [19] asserts that higher education institutions urgently need to create conditions for honest debate. Sensitive or underlying topics might become more prevalent in conversations after these issues have been unveiled in safe, facilitated discussions. Greene [11] is convinced that "encounters with the arts" can foster growth in young people so that they can find their voices in the public domain. The case study reported on in this article attempted to create such an encounter with the arts so as to ascertain the relevance of catalyzing "thought-provoking questions" [6] and creating platforms where the "roots of civic-mindedness" can develop [30].

\section{Conclusion}

The potential success of the artwork "We Belong Here" lies in its ability to create visual metaphors that translate philosophical ideas into practice and access the subconscious in an immediate way. The participants motivated that the University should drive opportunities where students can learn to deal with other points of view and perhaps alter theirs in positive ways. The artwork was regarded a safe space where expression, idea sharing, and discourse could take place. The participants also acknowledged that the artwork sparked students' interaction with a relevant social 
issue. Despite the fact that a few participants described their peers as ignorant and apathetic, most concluded that they all need to start taking up responsibility for causes on behalf of others. Students need to feel a sense of pride and belonging before they can excel in higher education. Participation in the artwork provides evidence that people are open to becoming involved and doing something. Interestingly, research participants associated the unique way in which people could participate in the artwork with the distinctive contributions that individuals make in their communities. Artworks with a relational purpose have the potential to create the kinds of spaces where people can articulate their opinions, pass on their ideas, and expose their fears. Public art can create lived experiences of the philosophical concepts that universities seek to instill in students. Art education in the expanded field can aid higher education institutions in bringing about personal and intellectual growth in the lives of their students. Such an initiative would allow students to be exposed to platforms where they can be immersed in critical conversations, gain confidence to share their opinions, be open to unexpected sources of learning, and relate their education to their future roles in society. Including public artworks in 'out-of-class learning' allows students to see their curricula as part of a complex education system that collaborates with other learning experiences on campus.

This article discussed the ways in which an expanded understanding of art and art education can facilitate discussions of ideological changes in higher education in South Africa. It did so through an analysis of data from interviews with participants on the public artwork "We Belong Here" and the discussion of the context of attempts to create shifts in the culture of Stellenbosch University.

\section{References}

[1] Krauss, R. (1979). Sculpture in the expanded field. October, 8: $30-44$.

[2] Harvey, L. and Knight, P. T. (1996). Transforming Higher Education. Bristol: Open University Press.

[3] Dei, G. J. S. and Kempf, A. (2006). Anti-colonialism \& Education. Rotterdam: Sense.

[4] Bourriaud, N. (2002). Relational Aesthetics. Paris: Les Presses du Reel.

[5] Johnson, L. and Morris, P. (2010). Towards a framework for critical citizenship education. Curriculum Journal, 21 (1): $77-$ 96.

[6] Adams, M., Bell, L and Griffin, P. (Eds.). (2007). Teaching for Diversity and Social Justice (2nd ed.). New York, NY: Routledge.

[7] Campbell, M. and Martin, R. (2006). Artistic Citizenship: A Public Voice for the Arts. New York, NY: Routledge.

[8] Greene, M. (1995). Releasing the Imagination. San Francisco, CA: Jossey-Bass.

[9] Darder, A., Baltodano, M. and Torres, R. D. (Eds.). (2003). The
Critical Pedagogy Reader. London: Routledge.

[10] Greene, M. (2013). The turning of the leaves: Expanding our vision for the arts in education. Harvard Educational Review, 83 (1): 251-253.

[11] Greene, M. (1995). Art and imagination: Reclaiming the sense of possibility. The Phi Delta Kappan, 76 (5): 378-382.

[12] Behari-Leak, K. (2015, November 18). After protests it can't be business as usual at South African universities. The Conversation. Retrieved from https://theconversation.com/after-protests-it-cant-be-businessas-usual-at-south-africas-universities-50548.

[13] Stellenbosch University. (2013). Institutional Intent and Strategy 2013-2018. Retrieved from http://www.sun.ac.za/english/management/rector/Documents/I nstitutional\%20Intent\%20and\%20Strategy\%202013-2018.pdf.

[14] Stellenbosch University. (2019). Vision 2040 and Strategic Framework 2019-2024. Retrieved from http://www.sun.ac.za/english/Documents/Strategic_docs/2018 /Vision-2040-Strategic-Framework-2019-2024.pdf.

[15] Badat, S. (2016). Deciphering the meanings, and explaining the South African higher education student protests of 2015-16. Retrieved

from http://wiser.wits.ac.za/system/files/documents/Saleem\%20Bad at $\% 20-\% 20$ Deciphering\%20the $\% 20$ Meanings, $\% 20$ and $\% 20$ Ex plaining\%20the $\% 20$ South $\% 20$ African $\% 20$ Higher\%20Educati on $\% 20$ Student $\% 20$ Protests.pdf.

[16] Stellenbosch University. (2014). Strategy for Teaching and Learning 2014-2018. Retrieved from http://www0.sun.ac.za/ctl/wp-content/uploads/2013/02/SU-ST RATEGY-FOR-TL-2014-2018.docx.

[17] Valley, G. (2014). What's the matter with... Stellenbosch University. Africa's A Country. Retrieved from https://africasacountry.com/2014/10/whats-the-matter-with-ste llenbosch-university/.

[18] Soudien, C., Michaels, W., Mthembi-Mahanyele, S., Nkomo, M., Nyanda, G., Nyoka, N.,... Villa-Vicencio, C. (2008, November 30). Report of the Ministerial Committee on Transformation and Social Cohesion and the Elimination of Discrimination in Public Higher Education Institutions. Retrieved from http://www.justice.gov.za/commissions/FeesHET/docs/2008Report-MinisterialCommittee-TransformationPHEI.pdf.

[19] Higher Education South Africa. (2010, March). Sector position paper on the report of the Ministerial Committee on Transformation and Social Cohesion and the Elimination of Discrimination in South Africa's Public Higher Education Institutions. Retrieved from http://www.education.gov.za/LinkClick.aspx?fileticket=jc97B om2utk\%3d\&tabid=191\&mid=484.

[20] Davids, N. and Waghid, Y. (2016, October 10). \#FeesMustFall: History of South African student protests reflects inequality's grip. Mail and Guardian. Retrieved from

http://mg.co.za/article/2016-10-10-feesmustfall-history-ofsouth-african-student-protests-reflects-inequalitys-grip.

[21] De Vos, A. S., Delport, C. S. L., Fouché, C. B. and Strydom, H. (2011). Research at Grass Roots: A Primer for the Social Science and Human Professions. Pretoria: Van Schaik. 
[22] Hesse-Biber, S. N. and Leavy, P. (2006). The Practice of Qualitative Research. New York, NY: Sage.

[23] Stellenbosch University. (2018). Statistical profile: Overview 2018.

$$
\text { Retrieved }
$$

from

http://www.sun.ac.za/english/statistical-profile-2014-test

[24] World Population Review (2020). South African population 2020 (live). Retrieved from https://worldpopulationreview.com/countries/south-africa-pop ulation

[25] Duncan, J. (2016, September 30). Why student protests in South Africa have turned violent. eNews Channel Africa. Retrieved from https://www.enca.com/opinion/why-student-protests-in-southafrica-have-turned-violent.

[26] Behari-Leak, K., Ramugondo, E. and Kathard, H. (2016,
October 11). Students in South Africa feel unheard, here's one way to listen. The Conversation. Retrieved from https://theconversation.com/students-in-south-africa-feel-unhe ard-heres-one-way-to-listen-66805.

[27] Gude, O. (2000). Investigating the culture of curriculum. In D. E. Fehr, K. Fehr and K. Keifer-Boyd (Eds.), Real-world Readings in Art Education: Things Your Professor Never Told You. New York, NY: Falmer Press, pp. 75-82.

[28] Apple, M. W. (1979). Ideology and Curriculum. London: Routledge.

[29] Palmer, J. (Ed.). (2001). Fifty Modern Thinkers on Education from Piaget to the Present. New York, NY: Routledge.

[30] Ramphele, M. (2001). Citizenship challenges for South Africa's young democracy. Daedalus, 130 (1): 1-17. 